\title{
Colonic obstruction following percutaneous endoscopic gastrostomy placement
}

A 64-year old man with a history of chronic obstructive pulmonary disease was admitted via the emergency clinic with respiratory failure. He was intubated and hospitalized in the intensive care unit. Because of difficulty weaning him from mechanical ventilation, a tracheostomy was performed. On the 20th day of hospitalization, a percutaneous endoscopic gastrostomy (PEG) tube was inserted. Enteral feeding was initiated, but abdominal distention and vomiting occurred almost immediately. The PEG tube was found to be intact on an endoscopic examination, but abdominal computed tomography (CT) demonstrated that the PEG tube was pulling both the anterior wall of the stomach and the transverse colon up against the abdominal wall ( $\bullet$ Fig. 1). A laparotomy was performed, which showed that the total colonic obstruction was caused by the walls of the colon being pressed against each other because the PEG tube was passing through the lumen of the transverse colon. The tube was detached, and a primary repair and percutaneous jejunal tube insertion were performed. The patient died on the 5th day after surgery as a result of septicemia.

Although PEG is a relatively safe procedure, serious complications may occur during or after tube insertion and removal, most of which are related to the comorbidities of the patient. Colonic perforation, gastrocolonic or colocutaneous fistula, and misplacement or migration of the PEG tube have all been recognized as rare but major complications [ 1 -3], which may occur soon after insertion or later, even years afterwards. Bowel obstruction resulting from incorrect tube removal has also been reported [4]. To our knowledge, this case with total occlusion of the colon due to a PEG is unique.

The risk of mistakenly inserting the needle into the colon during PEG placement is increased particularly when there is a

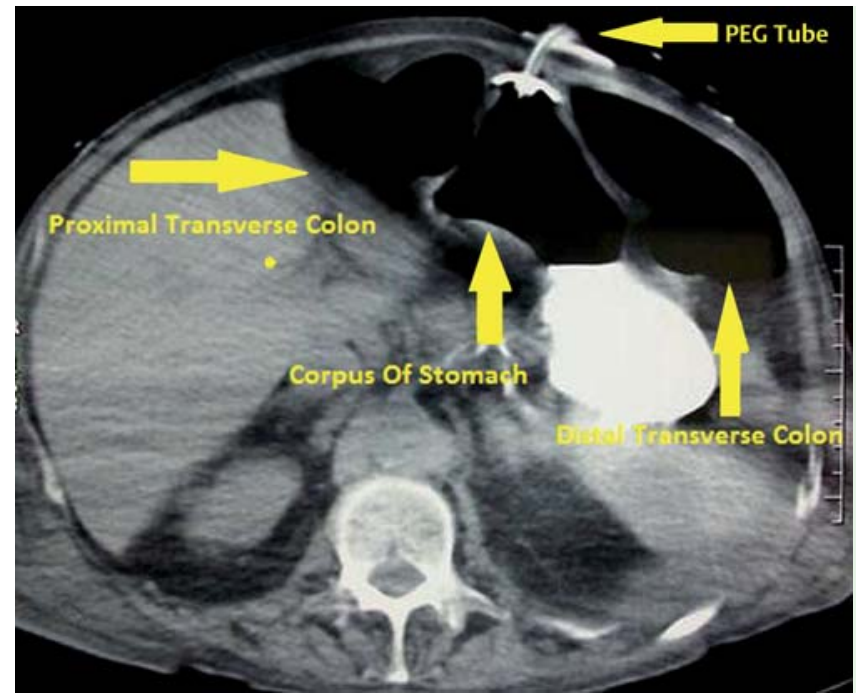

Fig. 1 Abdominal computerized tomography $(C T)$ scan showing the transverse colon sandwiched between the stomach and the abdominal wall having been pulled up by the percutaneous endoscopic gastrostomy (PEG) tube.

megacolon, subphrenic transposition of the colon, or a history of previous abdominal surgery [2]; however, none of these risk factors were present in our case. In most cases, tubes that have migrated into the colon can be removed without the need for surgery. When a fistula is identified, conservative treatment and close monitoring of the patient may be sufficient to allow healing. However, in other cases, such as this one, surgery may be mandatory.

Endoscopy_UCTN_Code_CPL_1AH_2AI

Competing interests: None

\section{H. Buluş ${ }^{1}$, S. Köklü ${ }^{2}$ A. Coşkun ${ }^{1}$, N. Dereli ${ }^{3}$, M. Akkoca ${ }^{1}$}

${ }^{1}$ Department of Surgery, Keçiören Training and Research Hospital, Ankara, Turkey

2 Department of Gastroenterology, Ankara Education and Research Hospital, Ankara, Turkey

${ }^{3}$ Department of Anaesthesiology and Reanimation, Keçiören Training and Research Hospital, Ankara, Turkey

\section{References}

1 Ward M, Rees C, Asthana AK et al. Colonic perforation during percutaneous endoscopic gastrostomy tube insertion with subsequent bumper migration into colon. Clin Gastroenterol Hepatol 2011; 9: e128

2 Friedmann $R$, Feldman $H$, Sonnenblick $M$. Misplacement of percutaneously inserted gastrostomy tube into the colon: report of 6 cases and review of the literature. JPEN J Parenter Enteral Nutr 2007; 31: 469-476

3 Liu SY, Ng SS, Yip HC et al. Migration of a percutaneous endoscopic gastrostomy tube into the transverse colon: a forgotten cause of refractory diarrhea. Endoscopy 2010; 42 (Suppl 2): E324-E325

4 Mutabagani KH, Townsend MC, Arnold MW. PEG ileus. A preventable complication. Surg Endosc 1994; 8: 694-697

Bibliography

DOI http://dx.doi.org/

10.1055/s-0031-1291750

Endoscopy 2012; 44: E179

(c) Georg Thieme Verlag KG

Stuttgart · New York

ISSN 0013-726X

\section{Corresponding author}

\section{S. Köklü, MD}

Bağlarbaşı mahallesi

Duman sokak, 55/11

06300, Keçiören

Ankara

Turkey

gskoklu@yahoo.com 